\title{
UNILATERAL FACET INTERLOCKING IN THE LOWER CERVICAL SPINE
}

\author{
R. BraAkman, Rotterdam, and P. J. Vinken, Amsterdam, The Netherlands
}

Interlocking of the zygapophysial joints of the lower cervical spine may occur on one or both sides. This paper reports thirty-seven cases of unilateral interlocking (hemiluxation).

In the literature unilateral interlocking is usually regarded as a form of dislocation, a term which includes other types of displacement as well. Thus, in the oldsr literature, the term dislocation often refers to an abnormal posture of the head (Langworthy 1930, Brookes 1933). Nowadays it is often used by radiologists to describe a shift of two vertebral bodies in relation to each other, and if this shift is slight the term subluxation is used. Such loose terminology may lead to inaccurate diagnosis and inappropriate treatment.

\section{MECHANISM}

Interlocking occurs when excessive flexion causes the inferior articular processes of the upper vertebra to move forwards over the tips of the superior articular processes of the lower vertebra (Fig. 1). Experience suggests that bilateral interlocking is caused by excessive flexion, and unilateral interlocking by simultaneous flexion and rotation.

Bilateral interlocking is always associated with rupture of the dorsal ligamentous apparatus, the capsules of the affected zygapophysial joints and the muscles. The annulus fibrosus is always damaged and often the anterior longitudinal ligament is torn from the lower vertebra. Occasionally, a fragment of the antero-superior part of this vertebra is torn off.

Unilateral interlocking usually occurs in the lower cervical spine (Table I). Damage to the ligaments and disc is often less severe than in bilateral interlocking. Beatson (1963) showed experimentally that the affected joint capsule and interspinous ligament must be torn to allow unilateral interlocking, whereas the posterior longitudinal ligament and the annulus fibrosus may be damaged only slightly. However, the lesions are usually more extensive. On the opposite side the ligaments of the zygapophysial joint are usually torn, and there is often a fracture of the superior articular process. Compression of the body of the vertebra immediately below the interlocking is often seen, and also there may be lesions elsewhere in the cervical spine. These differences between unilateral and bilateral interlocking were thoroughly described as early as 1855 by Malgaigne.

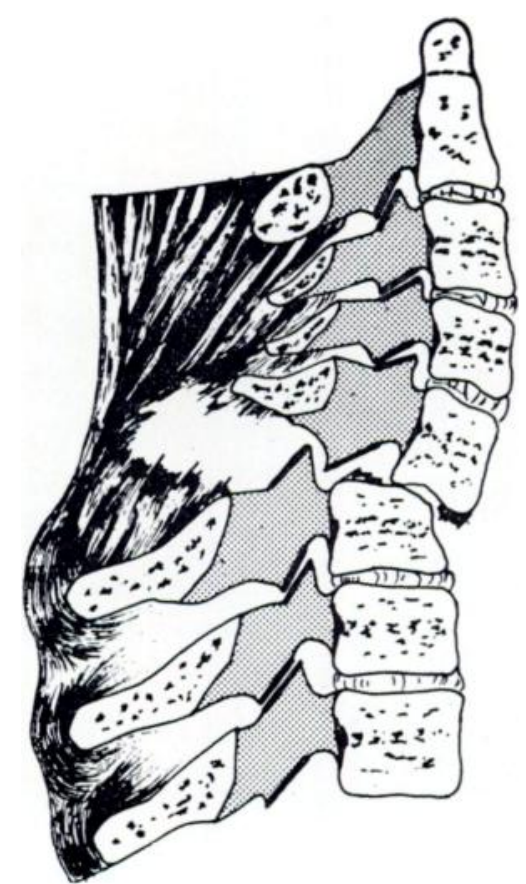

FIG. 1

Interlocking of the articular processes of C.5-C.6 (drawing after Böhler).

\section{CLINICAL FEATURES}

The clinical symptoms of cervical hemiluxation are not very specific. Pain in the neck is common but it may be very mild. The head may be held in a position of slight flexion, or slight rotation, due to muscular spasm and not, as is often believed, to the interlocking. 
Neurological symptoms of radicular or spinal cord origin are often encountered, but not always. Cord symptoms are due to deformation of the vertebral canal, especially narrowing in the sagittal plane. In bilateral interlocking the canal is narrowed much more than in unilateral interlocking, which explains the difference in severity of the neurological conditions (Table II, Figs. 2 to 4). Asymmetrical partial cord lesions are more pronounced on the side of the interlocking in unilateral cases. Radicular symptoms are due to deformation of the intervertebral foramen at the site of the interlocking. They are often present in cases of unilateral interlocking. Serious spinal cord lesions, however, which occur more often in bilateral interlocking, can mask associated root lesions and thereby prevent their recognition.

TABLE I

Site of Cervical Hemiluxations

\begin{tabular}{|c|c|c|c|c|c|c|c|c|}
\hline \multirow{2}{*}{\multicolumn{2}{|c|}{ Hemiluxation }} & \multicolumn{7}{|c|}{ Levels } \\
\hline & & C.2-C.3 & C.3-C.4 & C.4-C.5 & C.5-C.6 & C.6-C.7 & C.7-T.1 & Total \\
\hline Recent & . & - & 2 & 7 & 4 & 7 & 2 & 22 \\
\hline Old . & . & 1 & 1 & 4 & 5 & 3 & 1 & 15 \\
\hline Total & . & 1 & 3 & 11 & 9 & 10 & 3 & 37 \\
\hline
\end{tabular}

TABLE II

Neurological Symptoms in Cervical InTERLocking

\begin{tabular}{|c|c|c|c|c|c|c|}
\hline & $\begin{array}{c}\text { No } \\
\text { symptoms }\end{array}$ & $\begin{array}{c}\text { Root } \\
\text { lesion }\end{array}$ & $\begin{array}{c}\text { Reversible } \\
\text { cord } \\
\text { lesion }\end{array}$ & $\begin{array}{c}\text { Persistent } \\
\text { partial } \\
\text { cord } \\
\text { lesion }\end{array}$ & $\begin{array}{c}\text { Persistent } \\
\text { total } \\
\text { transverse } \\
\text { lesion }\end{array}$ & $\begin{array}{l}\text { Progressive } \\
\text { cord lesion }\end{array}$ \\
\hline Unilateral interlocking & 7 & 18 & 7 & 2 & 3 & 0 \\
\hline Bilateral interlocking . & 3 & 4 & 1 & 7 & 18 & 2 \\
\hline
\end{tabular}

The symptoms in a case of hemiluxation may be so slight that the patient does not consult his doctor, or the doctor may fail to ask for radiological examination. In fifteen of our thirty-seven patients the hemiluxation was diagnosed more than two weeks after injury. Sometimes months and occasionally years may elapse before hemiluxation is recognised.

\section{ILLUSTRATIVE CASE REPORT}

A woman aged twenty-seven was admitted to hospital after a road traffic accident with pain in the neck and tingling in both arms. With the exception of a positive Babinski reflex on the left side the neurological examination revealed no other abnormalities. Radiographic evidence of hemiluxation of C.5 on C.6 on the left was present but not recognised (Figs. 5 and 6). The diagnosis of subluxation was made and the patient was treated by traction of 6 kilograms applied to the skull through a Crutchfield caliper. After six weeks the interlocking was recognised; the antero-posterior projection showed the typical displacement to the left of the spinous process of C.5 (Fig. 7). She was subsequently treated with a plastic collar. Eight years later she complained only of slight pain in the neck. Radiologically, no movement took place at C.5-C.6, the C.5-C.6 disc space was abnormally thin. At the site of interlocking the articular processes appeared to have fused together (Fig. 8).

\section{RADIOLOGICAL FEATURES}

Unilateral interlocking can only be diagnosed radiologically, the appearances being characteristic. In the lateral projection the zygapophysial joint on one side is displaced (Figs. 5 and 6); in the antero-posterior projection the spinous process is usually displaced to the 
side of the interlocking. The upper vertebral body may show a lateral flexion deformity relative to the lower body (Fig. 7). If there is also a ligamentous lesion with a flexion deformity of the opposite joint, these features are more difficult to recognise. Stereoscopic films then become essential. If necessary, oblique (three-quarters view) films or those of Buetti-Bäuml (1954) should be taken. In exceptional cases, as in unilateral interlocking of C.7-T.1, tomographs are required.

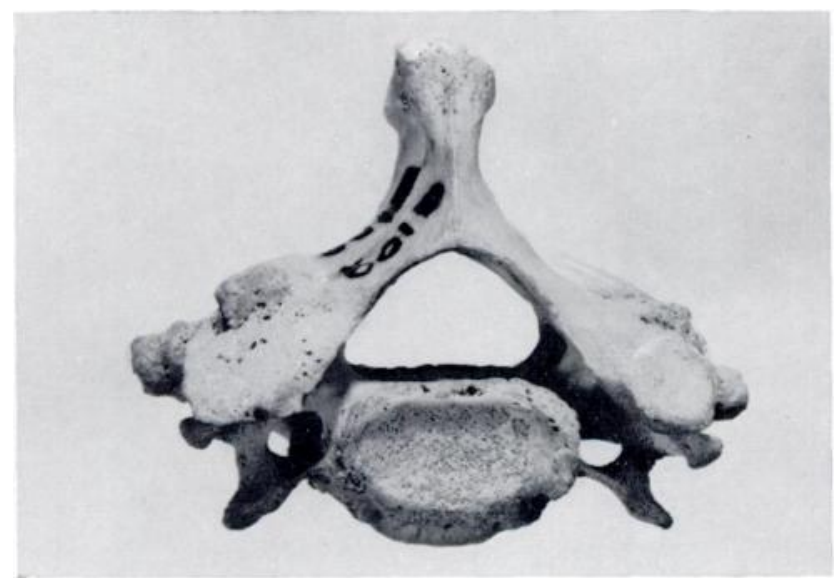

Fig. 2

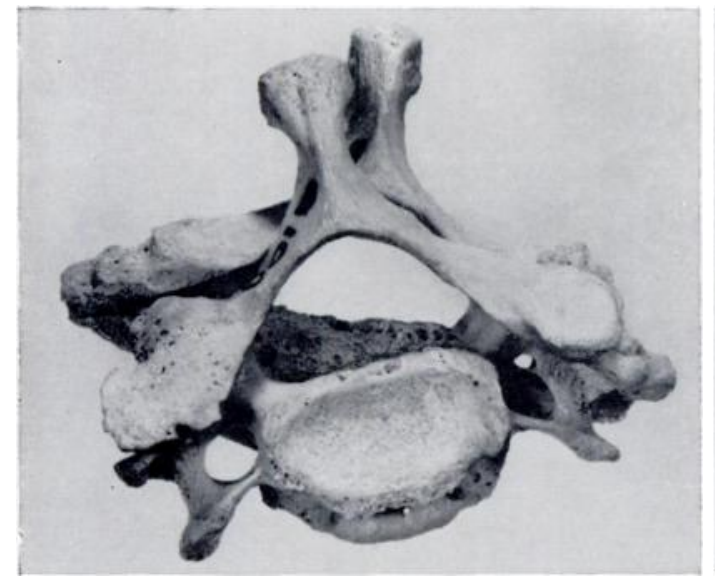

FiG. 3

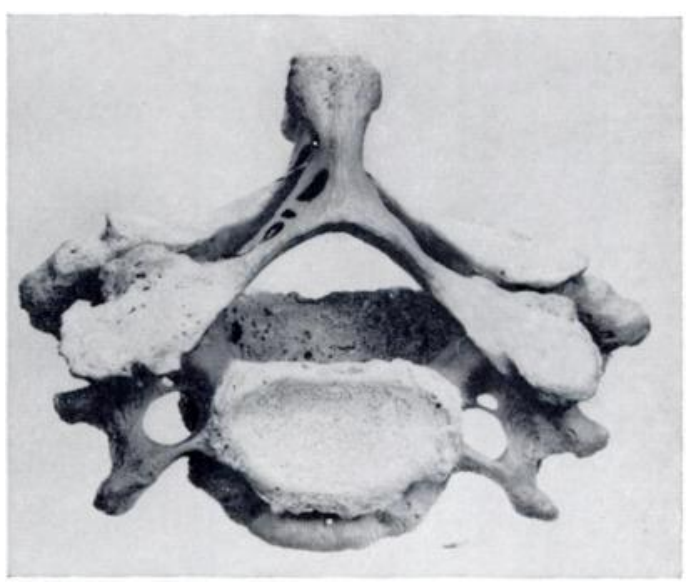

Fig. 4

Figure 2-Normal spinal canal as seen from above (C.5-C.6). Figure 3-Showing deformity and narrowing of the spinal canal in unilateral interlocking C.5-C.6, and the displacement of the spinous process of C.5 to the side of the interlocked intervertebral joint. Figure 4-Extreme narrowing of the spinal canal in bilateral interlocking C.5-C.6.

Although the radiological features of unilateral interlocking are well known, the diagnosis is often missed as too much attention is given to the shift of the vertebral bodies in relation to one another, and the essential lesion, the interlocking, is overlooked. Sometimes, also, the diagnosis is missed because the lower cervical vertebrae are not adequately demonstrated.

\section{TREATMENT}

Treatment consists of reduction and stabilisation. The displacement can be reduced only if the interlocked inferior articular process of the upper vertebra can be moved back over the tip of the superior articular process of the lower vertebra (Fig. 9). Several methods may be 


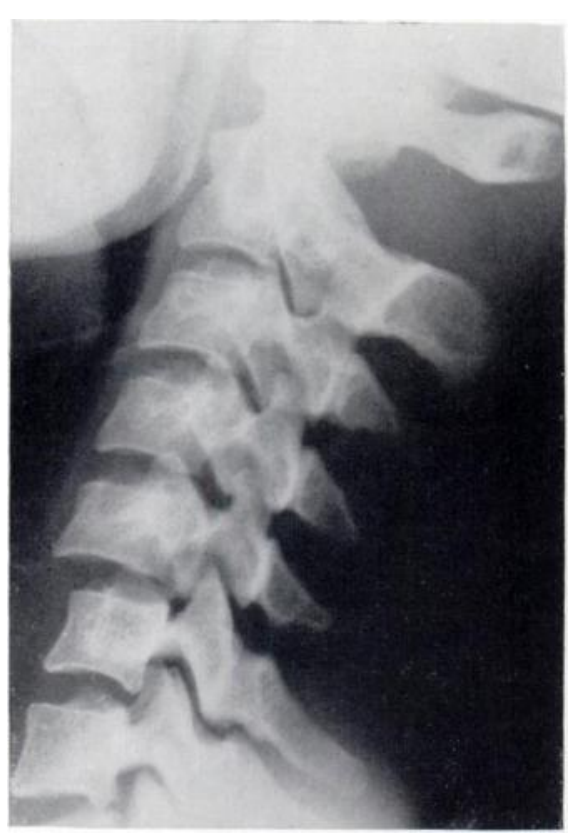

FIG. 5

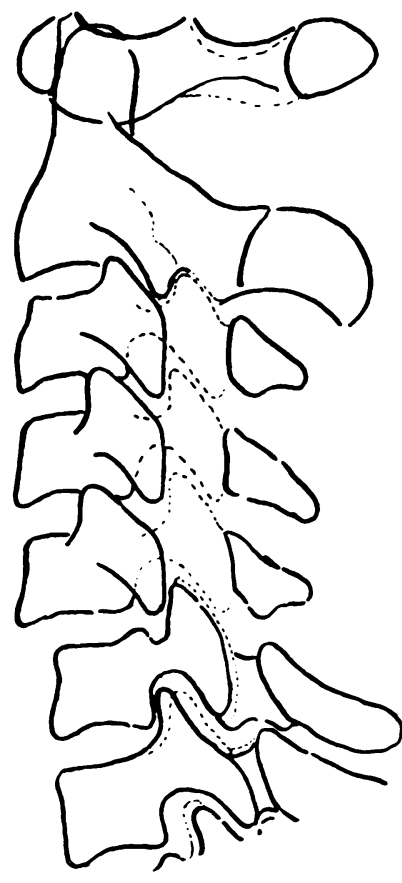

FIG. 6

Figure 5-Lateral radiograph of cervical spine, showing unilateral interlocking C.5-C.6. Figure 6-Schematic representation of the unilateral interlocking C.5-C.6 shown in Figure 5.

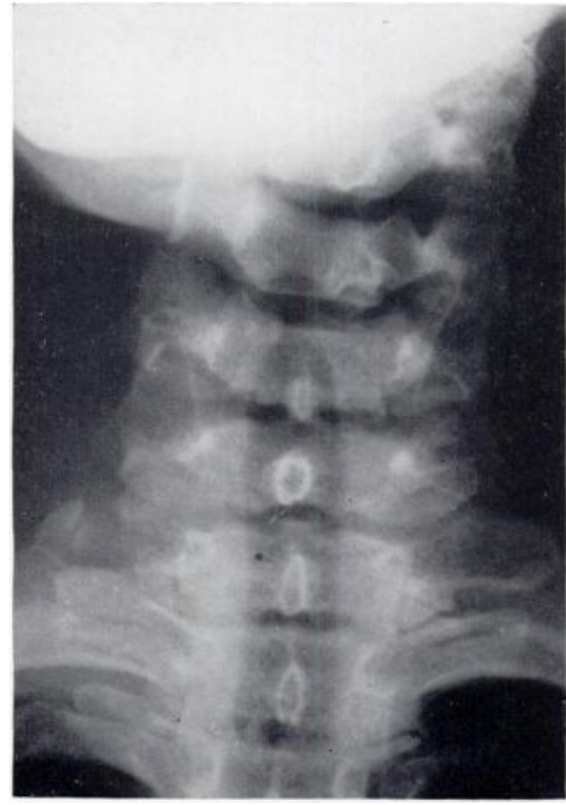

FIG. 7

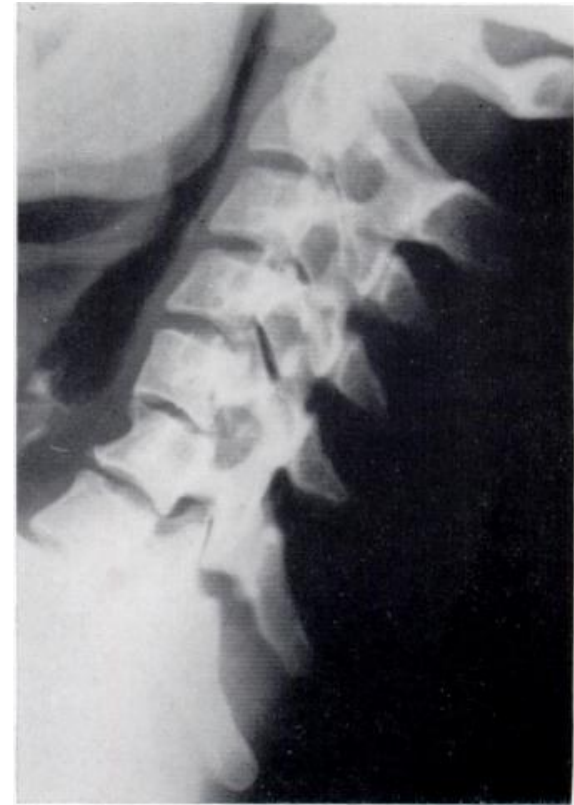

FIG. 8

Figure 7-Unilateral interlocking C.5-C.6 on the left, showing lateral dislocation of the spinous process of C.5 to the side of the interlocking. The body of C.5 has assumed an oblique position, its right side lying lower than its left side. Figure 8-Unilateral interlocking C.5-C.6 eight years after injury without reduction, showing ankylosis of the luxated zygapophysial joint. 
used and skull traction with a caliper is the usual one. Attempts have been made to achieve reduction within a few hours, using heavy weights (Böhler 1953), or within a few days using lighter weights (Crutchfield 1954, Paillas and Sedan 1959). This technique is often successful but may fail, especially in cases of hemiluxation. It failed in five patients treated by Rogers (1957) for unilateral interlocking. In fifteen cases of unilateral and bilateral interlocking reported by Ramadier and Bombart (1964), reduction was obtained in only eight cases, using skull traction with a weight of 10 kilograms.

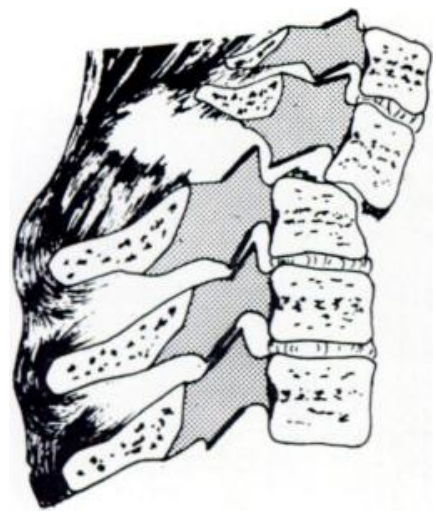

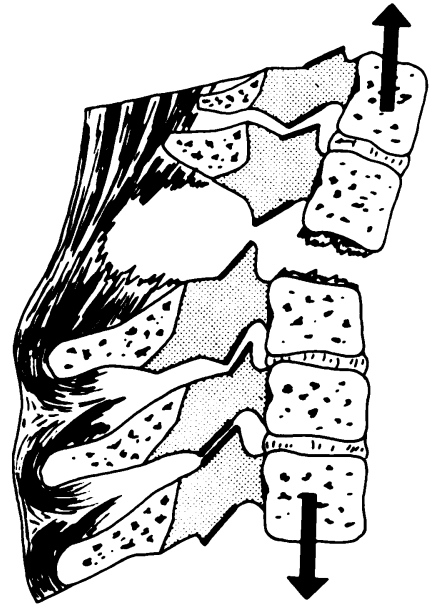

FIG. 9

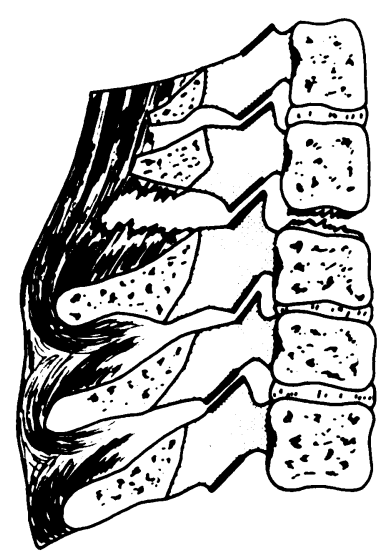

6 (drawing after Böhler).

Thirty years ago manual reduction was often used (Brookes 1933), but this method has gradually become less popular with the introduction of the skull caliper and operative reduction. It became less popular by reports of cases in which the manipulation was followed by neurological lesions, probably associated with insufficiently deep anaesthesia. In the English literature manual reduction was therefore regarded as obsolete until Evans (1961) recommended it again. In Europe, on the other hand, the method has always remained in use. Galibert (1962) achieved reduction with manual traction for several hours, by means of a loop, in twenty-four out of twenty-five patients without anaesthesia. Böhler (1953) and Bürkle de la Camp (1959) regarded manual reduction as the method of choice and they have applied it successfully in many cases.

Surgical reduction is preferred by those who consider internal fixation necessary for stabilisation of the cervical spine (Rogers 1957; Forsyth, Alexander, Davis and Underdal 1959). Reduction is achieved by skull traction and, if necessary, with instruments at operation with the patient in the prone position. Sometimes it is necessary to remove, partly or completely, a superior articular process. In recent years the antero-lateral approach has been used when it is no longer possible to eliminate the interlocking by skull traction (Verbiest 1962), or for the purpose of fixation (Cloward 1961, Verbiest 1962, Robinson 1964).

Fixation can be achieved by prolonged bed rest, immobilisation in a Minerva plaster, or by operation. Surgical fixation can be achieved by cerclage, posterior fusion, a combination of the two, or interbody fusion. It can be done immediately after reduction, or later if in spite of immobilisation in a Minerva cast a local kyphosis recurs with deformation of the spinal canal.

\section{DISCUSSION}

Low cervical hemiluxation is so rare (in the Netherlands it occurs in approximately one per two million of the population per year) that no single clinic can gain sufficient experience 
to judge the best method of treatment. This relatively large series was collected from three neurosurgical clinics; the patients showed differing abnormalities, and were treated in different ways. We have subdivided the cases into two groups: recent hemiluxations, treated within two weeks of injury, and old hemiluxations in which treatment could only be started two weeks or more after injury. An interval of two weeks was chosen as experience has shown that after this period the chances of successful reduction by simple means decrease rapidly.

TABLE III

THE ROOT LESIONS

\begin{tabular}{|c|c|c|}
\hline Hemiluxation & After reduction & Without reduction \\
\hline Recent & $\begin{array}{l}5 \text { cured } \\
\text { None persistent }\end{array}$ & $\begin{array}{l}\text { None cured } \\
3 \text { persistent }\end{array}$ \\
\hline Old & $\begin{array}{l}1 \text { cured } \\
3 \text { persistent }\end{array}$ & $\begin{array}{l}3 \text { cured } \\
3 \text { persistent }\end{array}$ \\
\hline
\end{tabular}

TABLE IV

Spinal Cord Lesions

\begin{tabular}{|l|c|l|}
\hline Hemiluxation & After reduction & Without reduction \\
\hline Recent & $\begin{array}{l}2 \text { cured } \\
4 \text { persistent }\end{array}$ & $\begin{array}{l}3 \text { cured } \\
\text { None persistent }\end{array}$ \\
\hline Old . & - & $\begin{array}{l}2 \text { cured } \\
1 \text { persistent }\end{array}$ \\
\hline
\end{tabular}

The question may be asked whether reduction of a hemiluxation is actually necessary. In our opinion it is certainly indicated in recent cases because: 1) in all patients with root symptoms these disappeared after reduction, whereas they persisted in all those in whom no reduction was obtained (Table III);2) the normal shapes of the spinal canal and intervertebral foramina are restored; and 3 ) there is little risk of aggravation of the neurological symptoms.

TABLE V

Results of Different Methods of Reduction in Cervical Hemiluxations

\begin{tabular}{|c|c|c|c|c|c|}
\hline Hemiluxation & $\begin{array}{l}\text { Manual reduction } \\
\text { under } \\
\text { general anaesthesia }\end{array}$ & $\begin{array}{c}\text { Caliper traction > } \\
10 \text { kilograms }\end{array}$ & $\begin{array}{c}\text { Caliper traction }< \\
10 \text { kilograms }\end{array}$ & $\begin{array}{c}\text { Surgical } \\
\text { reduction }\end{array}$ & No reduction \\
\hline Recent. & $\begin{array}{l}8 \text { succeeded } \\
2 \text { failed }\end{array}$ & $\begin{array}{l}2 \text { succeeded } \\
3 \text { failed }\end{array}$ & 5 failed & 4 succeeded & 3 \\
\hline Old & $\begin{array}{l}1 \text { succeeded } \\
2 \text { failed }\end{array}$ & 1 succeeded & 1 failed & 5 succeeded & 6 \\
\hline
\end{tabular}

In such a small number of cases the effect of reduction on spinal cord involvement remains uncertain. It may be supposed, however, that the prognosis of cord involvement is determined by the nature of the neurological lesion rather than by reduction or not. For instance, in three patients with partial transverse lesions all cord symptoms disappeared although no reduction was carried out, whereas they persisted in four patients with total transverse lesions 
after reduction (Table IV). However, reduction is indicated in cases of total transverse lesion, as the recovery of a possible radicular lesion (masked by the transverse lesion) may considerably reduce the patient's ultimate motor disability.

In cases of hemiluxation of longer standing, the effect of reduction on the neurological deficit is uncertain. Recovery from radicular and spinal cord symptoms has been seen with and without reduction, whereas in some cases the symptoms persisted (Tables III and IV).

In our cases reduction was carried out by operative or non-operative methods. Table $\mathrm{V}$ shows that in cases of recent hemiluxation manual traction under general anaesthesia was often successful, skull traction for several days with a weight of more than 10 kilograms was sometimes successful, and protracted skull traction with weights of less than 10 kilograms was never successful. Operative reduction was always successful, including those cases in which closed methods had failed. In old cases the operative method gave the best chance of a good result. None of our attempts at reduction caused aggravation of the neurological deficit.

In unilateral interlocking there is a tendency to spontaneous stabilisation regardless of whether reduction is carried out or not, and healing of the lesion leads to radiologically visible alterations. The damaged disc grows thinner; sometimes ossification develops in the outer edge of the annulus fibrosus and ultimately connects the adjacent vertebral bodies, and osteoarthritis develops in the zygapophysial joints. In the absence of reduction the interlocking articular processes may undergo bony fusion, and bone formation may be seen in the interspinous ligaments. We have seen a case in which ossification of the ligamentum flavum occurred (Fig. 10). Nearly always the affected segments become immobile even in the interlocked state; sometimes there is some residual mobility but the risk of later progressive neurological symptoms is small in cases of hemiluxation without reduction. The treatment of the present group of patients was not based on any

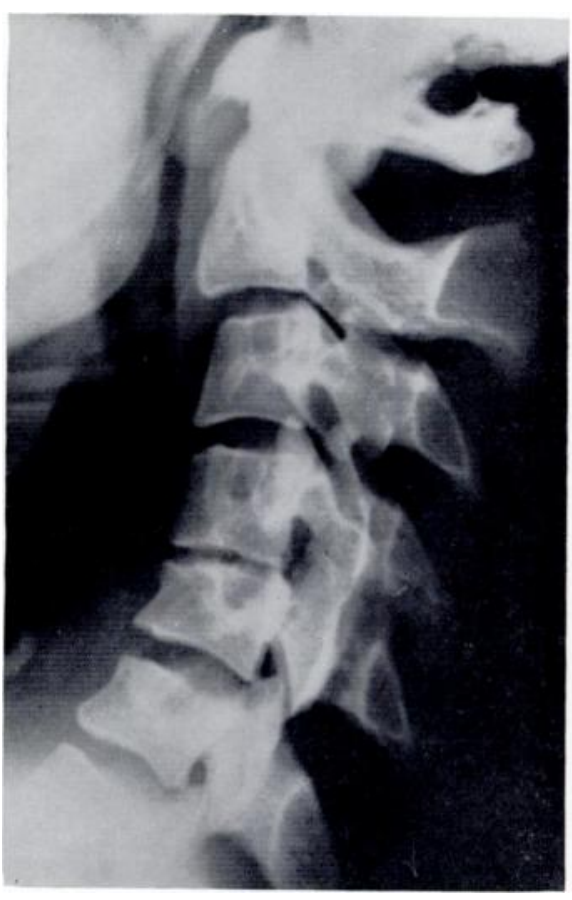

FIG. 10

Unreduced unilateral interlocking C.4-C.5 after five years, showing calcification of the ligamentum flavum, narrowing of the C.4-C.5 intervertebral space and bony ankylosis of the interlocked articular processes. preconceived theory and accordingly various forms of fixation have been used, such as a plaster jacket, internal fixation, combination of internal fixation and a plaster jacket or no fixation at all. In many cases the neurosurgeon in charge has not recorded his reasons for selecting a particular form of fixation. In all cases the affected segments became immobile, regardless of the type of fixation applied. For this reason it is difficult to recommend a method of choice.

In the presence of a transverse lesion treatment by a plaster jacket is impossible because of the danger of decubitus, but on the other hand, surgical fixation is not necessary in a number of cases. Bed rest on a Stryker frame usually leads to stabilisation. If there is severe damage to the cervical vertebrae, such as a fracture of the opposite articular process, a compression fracture of the vertebra below or a severe anterior displacement, a combination of internal and external fixation will be indicated more often than when damage is less severe. For the milder lesions, a plaster cast (Minerva type) for two or three months has been found to be the best form of treatment. In our opinion surgical treatment seems to be not so frequently necessary as is often asserted in the literature. 


\section{CONCLUSIONS}

Bilateral interlocking of the articular facets of the cervical spinal column results from excessive flexion. Unilateral interlocking (hemiluxation) results from simultaneous excessive flexion and rotation. Patients with hemiluxation of the cervical spine often have only mild complaints and the clinical signs may be slight. The diagnosis is made radiologically, but it is often overlooked.

Various forms of treatment may give good results. In recent hemiluxation, reduction is advisable to promote recovery of radicular symptoms. The effect of reduction on spinal cord symptoms is uncertain. Manual reduction under general anaesthesia is usually successful,

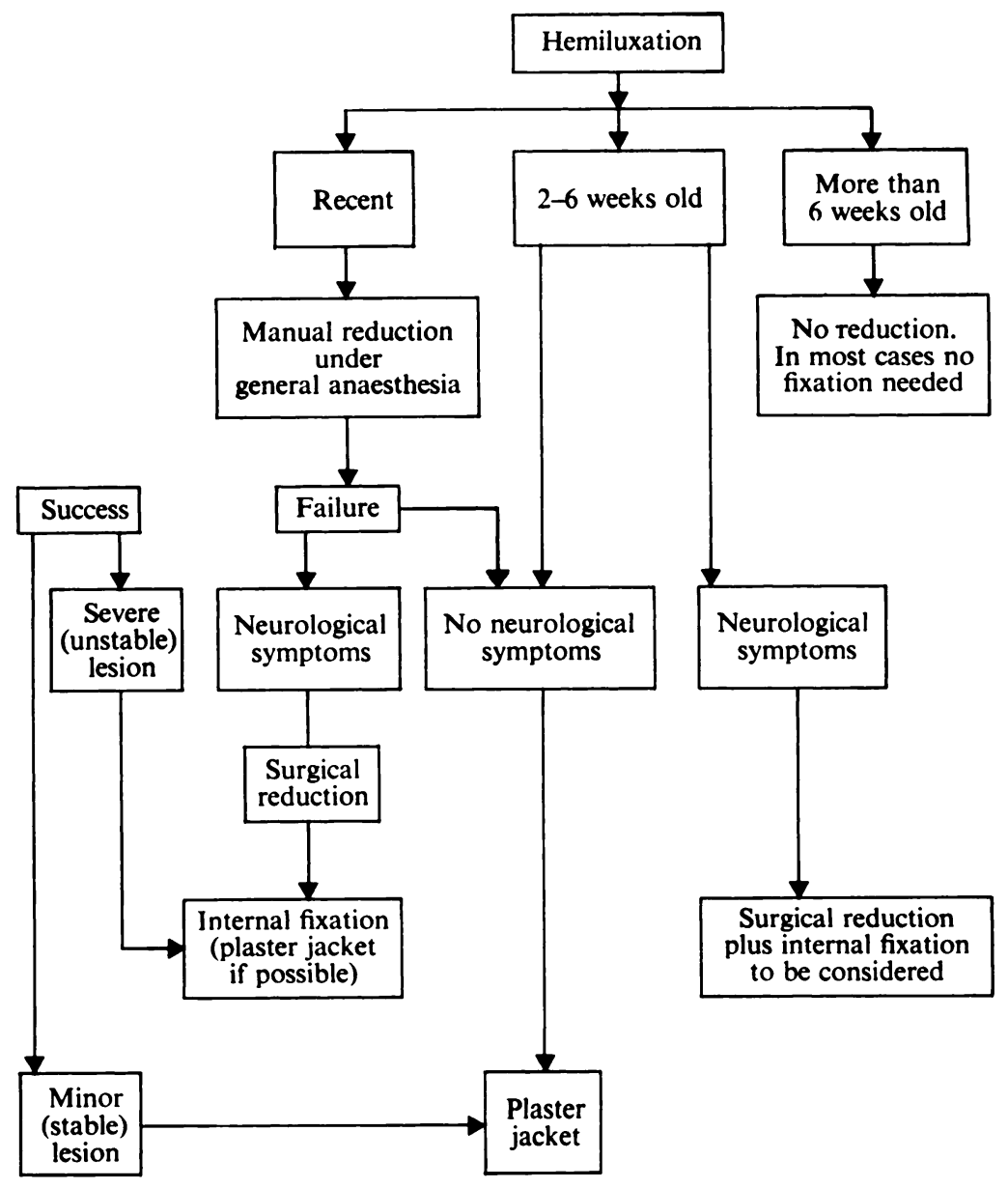

FIG. 11

Showing the methods of treatment used.

with the possible exception of some cases of interlocking at C.6-C.7,or C.7-T.1. Skull traction with weights of 5 to 10 kilograms even when prolonged is hardly ever successful; with weights of 10 kilograms or more there is a chance of success. Surgical reduction is not always necessary. A hemiluxation of more than two weeks' standing may still be reduced but non-operative methods offer little chance of success. In this series there has been no aggravation of the neurological deficit after reduction. Although hemiluxation shows a tendency to spontaneous stabilisation it is wise in our opinion to apply some form of fixation. The selection of the method of fixation depends on the neurological picture and on the estimated degree of 
instability. The latter depends on the presence or absence of additional damage to the interlocked and adjacent vertebrae. Manual reduction by means of traction in the longitudinal axis of the cervical spine under general anaesthesia with muscle relaxation, followed by immobilisation in a plaster jacket (Minerva type) for three months is successful in many cases. If surgical stabilisation is considered necessary an attempt at manual reduction should be made before operation so that when the patient is placed on the table the cervical spinal canal has regained its normal shape. In general, sufficient stability will have been achieved after approximately three months, so that for hemiluxations of more than three months duration surgical treatment will only rarely be necessary. Figure 11 shows the methods of treatment that we advise.

This study was based on clinical records from the Neurosurgical University Clinic of Amsterdam (Professor Dr W. Noordenbos), the Neurosurgical University Clinic of Groningen (Professor Dr C. H. Lenshoek) and the Neurosurgical Clinic of Dijkzigt Hospital, Rotterdam (Dr S. A. de Lange). Permission for studying these records and publication of the results is gratefully acknowledged.

\section{REFERENCES}

Beatson, T. R. (1963): Fractures and Dislocations of the Cervical Spine. Journal of Bone and Joint Surgery, 45-B, 21.

BöHLer, L. (1953): Die Technik der Knochenbruchbehandlung. 12e und 13e Auflage, Band I. Wien: Wilhelm Maudrich Verlag.

Brookes, T. P. (1933): Dislocations of the Cervical Spine, their Complications and Treatment. Surgery, Gynecology and Obstetrics, 57, 772.

Buetti-Bäuml, C. (1954): Funktionelle Rontgendiagnostik der Halswirbelsäule. Stuttgart: Georg Thieme Verlag.

Bürkle de la CAMP, H. (1959): Zur Behandlung der Halswirbelluxationen. Archiv für Klinische Chirurgie, 292, 514.

Cloward, R. B. (1961): Treatment of Acute Fractures and Fracture-dislocations of the Cervical Spine by Vertebral-Body Fusion. A Report of Eleven Cases. Journal of Neurosurgery, 18, 201.

Crutchfield, W. G. (1954): Skeletal Traction in Treatment of Injuries to the Cervical Spine. Journal of the American Medical Association, 155, 29.

Evans, D. K. (1961): Reduction of Cervical Dislocations. Journal of Bone and Joint Surgery, 43-B, 552.

Forsyth, H. F., Alexander, E., Jun., Davis, C., Jun., and Underdal, R. (1959): The Advantages of Early Spine Fusion in the Treatment of Fracture-Dislocation of the Cervical Spine. Journal of Bone and Joint Surgery, 41-A, 17.

GaliberT, P. (1962): Une méthode de traitement des luxations du rachis cervical compliquées de lésions médullaires ou radiculaires. Lille Chirurgical, 17, 172-180.

Langworthy, M. (1930): Dislocations of the Cervical Vertebrae. Report of 30 Cases. Journal of the American Medical Association, 94, 86.

Malgaigne, J. F. (1855): Traité des fractures et des luxations. Tome 2: Des luxations. Paris: J. B. Baillière.

Paillas, J. E., and Sedan, R. (1959): Fractures et luxations du rachis cervical. Journal de Chirurgie (Paris), 77, 50.

Ramadier, J. O., and Bombart, M. (1964): Fractures et luxations du rachis cervical sans lésions médullaires, 2ème partie. Lésions des 5 dernières vertèbres cervicales. Revue de Chirurgie Orthopédique, 50, 3.

Robinson, R. A. (1964): Anterior and Posterior Cervical Spine Fusions. Clinical Orthopaedics and Related Research, 35, 34.

Rogers, W. A. (1957): Fractures and Dislocations of the Cervical Spine. An End-result Study. Journal of Bone and Joint Surgery, 39-A, 341.

Verbiest, H. (1962): Anterior Operative Approach in Cases of Spinal-cord Compression by Old Irreducible Displacement or Fresh Fracture of Cervical Spine. Journal of Neurosurgery, 19, 389. 